In the latter it was found that the cervical trigeminal nucleus and the nerve cell of the upper cervical sensory nerves converged in the dorsal horn gray matter of these segment. Furthermore, the spinal descending nucleus of the $\mathrm{V}$ was demonstrated as caudally as $\mathrm{C}_{\mathrm{IV}}$ in the dog. This fact is thought to be a contribution to the dissolution of a mechanism of intractable headache.

\title{
111. Intrathecal Injection of Phenol-Myodil Solution for Relief of Intractable Pain
}

\author{
Hiromu Takebayashi, Norihiko KomaI, Ichiro Fujita \\ Masaji KIsHI and Susumu BookA \\ 1st Department of Surgery, Wakayama Medical College
}

Various kinds of procedures (rhizotomy, tractotomy, chordotomy, thalamotomy, intrathecal injection of alcohol, etc.) have been attempted to treat intractable pain. These methods, however, were of limited indications, because they sometimes resulted in great lesions or serious complications.

In 1955 Maher got success to inject a phenol solution into the intrathecal space in order to relieve intractable pain without any nervous destructions.

We tried also to inject a phenol-myodil solution into the intrathecal space in patients who had complained of intractable pains caused by malignant tumors in the pelvic cavity, tabes dorsalis and Buerger's disease, etc., then investigated the ideal concentration of phenol-myodil solution, its effects and side actions. We used $0.5 \sim 1.2 \mathrm{cc}$ of $3 \sim 7 \%$ phenol-myodil solution, which was injected into the spinal canal at the defined level in the lateral posion. According to circumstances, we controlled the level under the fluoroscopic examination. On the occasion of success, pains usually disappeared in 30 seconds after the intrathecal injection. The effects continued permanently without abnormal sensations of touch, pinprick and muscular weakness. Complications were mostly transient. 